\title{
Biocomposite Fiber-Matrix Treatments that Enhance In-Service Performance Can Also Accelerate End-of-Life Fragmentation and Anaerobic Biodegradation to Methane
}

\author{
Authors: Cecily A. Ryan, Sarah L. Billington, \& \\ Craig S. Criddle
}

The final publication is available at Springer via http://dx.doi.org/10.1007/s10924-017-1068-4.

Ryan, Cecily A., Sarah L. Billington, and Craig S. Criddle. "Biocomposite Fiber-Matrix Treatments that Enhance In-Service Performance Can Also Accelerate End-of-Life Fragmentation and Anaerobic Biodegradation to Methane." Journal of Polymers and the Environment (July 2107): 1-12. DOI: 10.1007/s10924-017-1068-4.

Made available through Montana State University's $\underline{\text { ScholarWorks }}$ scholarworks. montana.edu 


\title{
Biocomposite Fiber-Matrix Treatments that Enhance In-Service Performance Can Also Accelerate End-of-Life Fragmentation and Anaerobic Biodegradation to Methane
}

\author{
Cecily A. Ryan ${ }^{1,2}$ (1) $\cdot$ Sarah L. Billington ${ }^{1} \cdot$ Craig S. Criddle $^{1}$
}

\begin{abstract}
Biodegradable resins can enhance the environmental sustainability of wood-plastic composites (WPCs) by enabling methane $\left(\mathrm{CH}_{4}\right)$ recovery via anaerobic digestion (AD). An under appreciated step in biocomposite $\mathrm{AD}$ is the role of cracking and fragmentation due to moisture uptake by the wood fiber (WF) fraction. Here, we use batch microcosms to simulate $\mathrm{AD}$ at end-of-life and to assess the effects of fiber-matrix treatments used to retard in-service moisture uptake. The composites evaluated were injection molded poly(hydroxybutyrate-co-hydroxyvalerate) (PHBV) with WF $(0,20 \%)$ using two fiber-matrix compatibilization treatments: (1) hydrophobic silane treatment of the wood fiber and (2) grafting of hydrophilic maleic anhydride groups to the PHBV matrix. Both treatments accelerated rates of mass loss and $\mathrm{CH}_{4}$ production by a factor of 1.2-2.3 compared to neat PHBV. The fragmentation rate, as measured by mass loss, increased significantly for treated samples compared to untreated samples. A ranking of test samples from lowest to highest rates of mass loss gave the following sequence: neat $\mathrm{PHBV} \approx$ maleated PHBV $<$ PHBV plus untreated $\mathrm{WF}<$ maleated PHBV plus untreated WF $<$ PHBV plus silane-treated WF. Compared to the untreated samples, maleic anhydride treatment increased the mass loss rate by $30 \%$, and silane treatment increased the mass loss rate by $92 \%$. Onset of cracking in silane-treated composites was observed at 2 weeks (using
\end{abstract}

$\mathrm{X}$-ray micro-computed tomography). At the same time, solid mass loss and $\mathrm{CH}_{4}$ production peaked, implicating cracking and physical disintegration as the rate-limiting step for accelerated anaerobic degradation. When modified to account for bioplastic matrix degradation, a previously derived moisture-induced damage model could predict the onset of composite fragmentation at end-of-life. These results are significant for design of bio-WPCs and demonstrate that treatments designed to improve in-service performance can also improve end-of-life options.

Keywords Biodegradable plastic $\cdot$ Biocomposite $\cdot$ Woodplastic composites $\cdot$ Anaerobic degradation $\cdot$ Fragmentation

\section{Introduction}

Wood-plastic composites (WPCs) have experienced significant growth over the last decade in many wood replacement applications, such as decking and furniture [1]. This growth has been driven by cost reduction and enabled by effective use of waste streams and improved in-use properties, such as dimensional stability and uniformity. As these products increase in volume, their environmental impact at end-of-life is likely to become significant. Materials used in residential construction, such as drywall, wood, and plastic composites makeup approximately $40 \%$ of the 100 million tons of construction and demolition debris (C\&D debris) landfilled annually in the United States [2-4]. As WPCs expand into this large-volume application space, and as landfill space becomes increasingly limited, new end-oflife options become more important.

Substituting biodegradable plastics for traditional plastics in WPCs (bio-WPCs) can potentially enable more environmentally sustainable material life-cycles [5]. An 
advantage of bio-WPC use in large-volume applications, is the potential for anaerobic digestion (AD) and recovery of methane $\left(\mathrm{CH}_{4}\right)$ at end-of-life. While some traditional plastics are recycled, downcycling of material properties makes them less suitable for their original application. Moreover, recycling of traditional WPCs is often infeasible because they are mixed materials and may already contain recycled plastic [6]. Biodegradation of bio-WPCs in a controlled anaerobic environment, such as an anaerobic digester, converts the biodegradable components into $\mathrm{CH}_{4}$, a feedstock for energy or chemical production. If the $\mathrm{CH}_{4}$ recovered is used as a feestock for de novo bioplastic production, chemical recycling without downcycling is feasible [7].

Although bio-WPC products have the potential for widespread use in the future, their degradation properties have received little attention compared to pure bioplastics. This lack of attention might reflect an assumption that composites will behave like bioplastics with an inert filler. But this assumption may not be correct given that biocomposites are complex structures, with fibers arranged in differing orientations and a diversity of fiber and bioplastic matrix treatments. In aerobic composting and soil burial studies, the presence of natural fibers and fiber treatments had variable effects on the rates of biodegradation of composites containing poly(hydroxybutyrate-co-hydroxyvalerate) (PHBV) $[8,9]$. In addition, some treatments applied to improve inservice performance (such as chromated copper arsenate commonly used to pre-treat wood products for moisture resistance) can lead to inhibition of AD [10]. Such studies underscore the need for biodegradation studies on bioWPCs that have been optimized for in-service properties.

Like in traditional WPCs and other natural fiber reinforced composites, reducing moisture absorption by the fibers in the bio-WPCs is important for in-service durability $[1,11-13]$. Srubar et al. evaluated two types of treatments to enhance the in-service moisture resistance of PHBV bio-WPCs: a silane treatment for the wood fiber (WF) and grafting maleic anhydride groups to a portion of the PHBV matrix $[12,14,15]$. For initial absorption of water into the composites, both treatments slowed moisture uptake [15]. However, in a fully saturated state, the treated composites exhibited less recoverability relative to the untreated samples, which was attributed to an increased degradation of the fiber-matrix interface [12]. Variability in fiber and matrix treatments could therefore impact rates of degradation at end-of-life. Given the potential for moisture uptake by and swelling of the natural fibers, fragmentation due to stresses within the bio-WPCs is likely to be a contributing factor for enhanced biodegradation as compared the neat bioplastic [12, 16, 17]. In addition to the physical effects of moisture uptake, the fiber-matrix interface in the composites provides surfaces and "freeways" for microbial and enzymatic ingress into bio-WPC samples. Such processes would further weaken the bioplastic matrix, making it more susceptible to internal stresses [16, 18-20].

In order to better understand the degradation process that these materials undergo at end-of-life in a simulated landfill environment or an $\mathrm{AD}$ resource recovery facility, we first present the theory behind the mechanisms of bioWPCs degradation and how current fiber saturation models can be applied. We then present experimental results that describe: (1) the accessibility of the fiber-matrix interface to enzymatic and microbial ingress, (2) the difference in mass loss and $\mathrm{CH}_{4}$ generation rates as an indication of fragmentation, and (3) the onset of cracking and fragmentation in the bio-WPCs. A primary goal of this work was to determine if current bio-WPC fiber saturation models could be used to explain the onset of cracking and fragmentation during $\mathrm{AD}$ of bio-WPCs and the resultant increase in mass loss and $\mathrm{CH}_{4}$ production rates as compared to those of neat bioplastic.

\section{Theory}

\section{Steps of Anaerobic Degradation in Bio-WPCs}

Figure 1 (panels a-c) illustrates mechanisms involved in the stepwise biodegradation of bioplastic (PHBV) and bioWPC (PHBV and WF). These steps are:

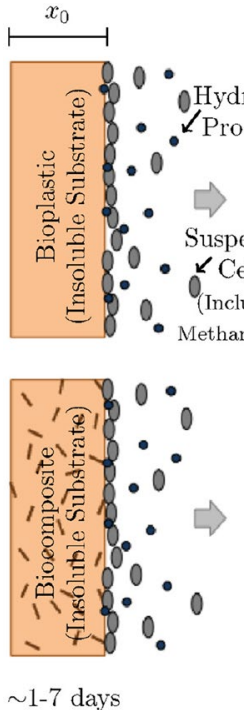

(a)
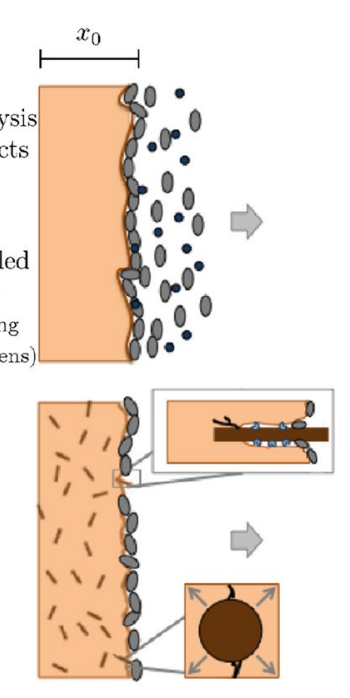

$\sim 7-10$ days

(b)
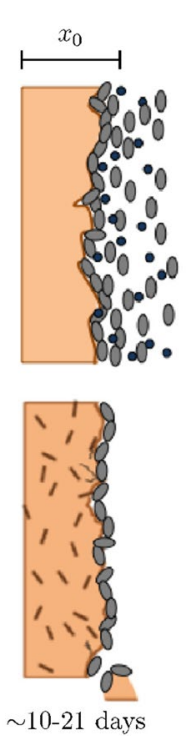

(c)
Fig. 1 Mechanisms of bioplastic and biocomposite degradation: a colonization by microorganisms and initiation of hydrolysis, $\mathbf{b}$ surface erosion of the bioplastic, saturation WF and initiation of moisture-induced cracking in the biocomposite, and continued surface erosion and roughening in bioplastic and composites with voids, inhomogeneities, and moisture uptake in the composites leading to fragmentation 
(a) [ 1-7 days, panel a] Colonization and initial biofilm formation occurs at the surface of the bioplastic or biocomposite, followed by secretion of hydrolytic enzymes.

(b) [ 7-10 days, panel b] Surface erosion of the bioplastic component occurs. In the bio-WPCs, enzymes can access the surfaces next to WF exposed to the media. The WF exposed to moisture becomes increasingly saturated, leading to cracking, which exposes additional surfaces to enzyme hydrolysis. Methane production initiates as hydrolysis products and intermediates become available to methanogenic biomass. Soluble products released by hydrolysis of the solid surface diffuse into the biofilm. Methane production initiates within the methanogenic community as soluble products degrade. From previous studies of biofilm formation in anaerobic reactors [21], it can be hypothesized that the methanogens will be present at the mediaexposed side of attached biofilms or as unattached cells in the media.

(c) [ 10-21 days, panel c] Surface erosion and roughening occurs at the solid surface, with voids and inhomogeneities leading to a small amount of fragmentation. Internal stresses are created within the bio-WPCs, due to the uptake of moisture and resultant swelling of the fibers. This fiber expansion leads to accelerated fragmentation of the biocomposite. If methanogenic activity is occurring throughout the film, trapped pockets of $\mathrm{CH}_{4}$ may contribute to fragmentation by creating additional internal stresses. Surface erosion of exposed surfaces continues. Methane production occurs near the maximum rate, as the surface area of the biopolymer exposed to microbial hydrolysis increases.

(d) [ 21-42 days] Once the solid substrate is mostly consumed, $\mathrm{CH}_{4}$ rate decreases to near zero, and the amount of $\mathrm{CH}_{4}$ released approaches the theoretical maximum (not shown).

\section{Model for Mass Loss and Methane Production}

Microbial growth can be described by several types of exponential functions. As substrate consumption and $\mathrm{CH}_{4}$ production are linked to this microbial growth during anaerobic degradation, these factors can also be described using exponential models [22-24]. The Gompertz model is commonly applied to $\mathrm{CH}_{4}$ production from a batch reactor [24, 25] and has been successfully used to simulate methane production from a landfill environment [26]. In related work, we found that the Gompertz model gave a good fit for $\mathrm{CH}_{4}$ production during anaerobic degradation of neat PHBV [27]. This model generates a single, sigmoidal curve based on the assumption that there is a lag time and that $\mathrm{CH}_{4}$ production is linked to specific growth rate. It is useful for describing $\mathrm{CH}_{4}$ production because it has relatively few fitting parameters, and these parameters have easily interpreted physical meaning. The equation is:

$P(t)=P_{m} \cdot \exp \left\{-\exp \left[\frac{R \cdot e}{P_{m}}(\lambda-t)+1\right]\right\}$

In this equation $P_{m}$ is the total methane production potential $[m L / g], R$ is the maximum specific $\mathrm{CH}_{4}$ production rate $[\mathrm{mL} / \mathrm{g} \cdot d a y]$, and $\lambda$ is the lag phase time, or delay to start of $\mathrm{CH}_{4}$ production [days].

The bio-WPCs are comprised of two potentially hydrolyzable substrates, WF and PHBV. When modeling two hydrolyzable substrates, a combined exponential model, such as was used by Gordon et al. for PHBV-starch composites, could be considered [28]. In this system, however, biodegradation of the WF is expected to minimally contribute to the $\mathrm{CH}_{4}$ generation for the composites, as lignocellulosic fibers break down slowly and incompletely to $\mathrm{CH}_{4}[29,30]$. A single sigmoidal function is therefore expected to provide an adequate fit to $\mathrm{CH}_{4}$ generation curves.

Some plastics and biodegradable plastics can break down, or fragment, without full conversion into $\mathrm{CH}_{4}$, leaving incomplete degradation products behind in the environment [17]. Therefore measurement of $\mathrm{CH}_{4}$ production, in addition to mass loss, is necessary for understanding of AD end-of-life options. For a biodegradable plastic that is readily converted to $\mathrm{CH}_{4}$, such as PHBV [31-34], mass lost from the bulk bioplastic is expected to undergo quick methanogenesis. Mass loss is therefore expected to correlate well with $\mathrm{CH}_{4}$ production, and surface erosion via microbial and enzymatic attack is expected to be the primary mechanism of degradation $[16,35,36]$. Mass loss occurs more rapidly than $\mathrm{CH}_{4}$ production if there is: (1) incomplete conversion of the lignocellulosic component into $\mathrm{CH}_{4}$ and/or (2) a mechanism other than surface erosion, such as fragmentation, is contributing to mass loss from the composites. In this case, understanding the role of fragmentation during the AD of bio-WPCs will enable better predictions of biodegradation and $\mathrm{CH}_{4}$ production rates.

In order to compare mass loss and $\mathrm{CH}_{4}$ production data for composites, the Gompertz equation (1) can be modified to express the model parameters in terms of percent. By dividing methane production potential $\left(P_{m}\right)$, by the theoretical potential $\left(P_{T H}\right)$, the function converges at a percent of the theoretical maximum $\left(P_{m} / P_{T H} \times 100 \%\right)$. Rates are then expressed in terms of percent of theoretical $\mathrm{CH}_{4}$ generated per day, with lag time expressed in days. Using a similar calculation, the Gompertz equation 
can then be used to fit the mass loss data in terms of percent of total mass lost, percent of total mass lost per day, and days. The theoretical value of $\mathrm{CH}_{4}$ production for PHBV can be calculated with stoichiometry and the value for the bio-WPCs established from chemical oxygen demand (COD) measurements, as described in Ryan et al. [37].

\section{Fiber-Saturation Modeling Applied to Degradation}

Previous work by Srubar et al. [12, 15] has characterized moisture absorption and moisture-induced damage of PHBV and WF composites similar to those investigated in this study: (1) PHBV with 0, 20, 40\% WF, (2) maleated PHBV with 0, 20, 40\% WF, and (3) PHBV with 20, 40\% silane-treated WF [14]. These studies found that water transport was greater in the composites than neat PHBV, with diffusivity increasing with WF content. They also found that fiber-matrix compatibilization treatments slowed moisture transport into the composites, but that the treated composites ultimately reached the same equilibrium moisture content as the untreated composites [15]. As enzymes require water transport into the sample to hydrolyze the bioplastic surface, the greater water uptake of the composites as compared to that of the neat PHBV should lead to more rapid degradation. In addition, if surface-erosion mechanisms are dominant in the bio-WPCs, enzyme transport would be expected to follow water transport into the composite and similar decreases in degradation rates with fiber-matrix compatibilization treatments might be expected.

The model of fiber-saturation for WPCs described above assumes a low fiber volume fraction and humidity such that significant moisture-induced damage due to fiber swelling would not occur. In developing a micromechanical model for moisture-induced deterioration in bio-WPCs, Srubar et al. found that at higher volume fractions (36-46\% WF) there was clear visual evidence of moisture-induced cracking and spalling, with the critical fiber volume threshold for moisture-induced cracking calculated as $31-38 \%$ WF [12]. This range is based on measured and theoretical moisture saturation contents of the WF: $23 \%$ moisture saturation for wood flour-polypropylene composites and 30\% moisture saturation for bio-WPCs $[12,38]$. The data for PHBV tensile strength and the model for moisture-induced orthoradial tensile stress are reproduced from Srubar et al. for $30 \%$ fiber moisture content in Fig. 2 [12].

The present study is focused on treated and un-treated composites with 0 and $20 \%$ fiber volume fraction. Based on the micromechanical model described above, fragmentation due to moisture-induced cracking of the composites during biodegradation would not be expected if only moisture saturation of the fibers were considered. However,

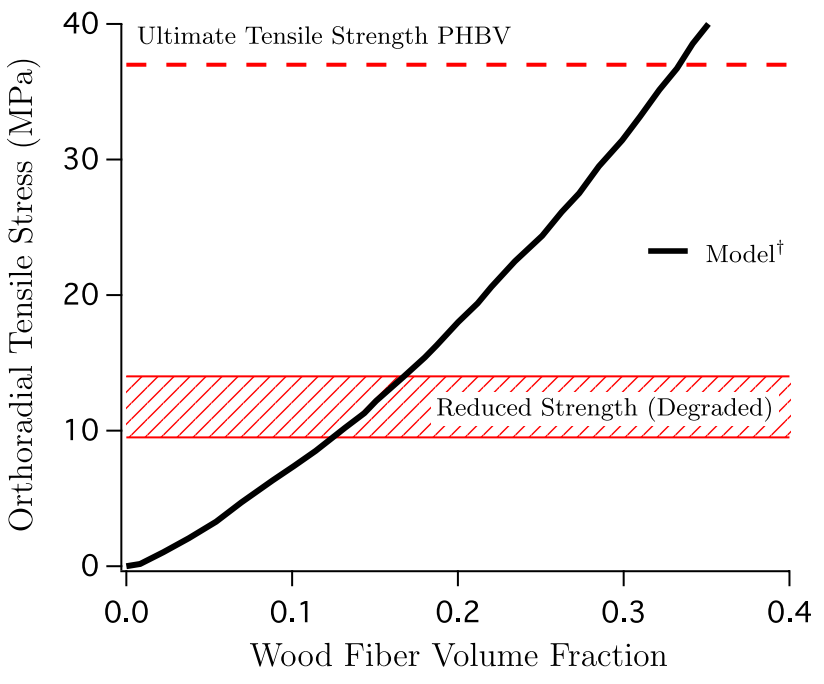

Fig. 2 Orthoradial tensile stress due to moisture-induced swelling of wood fibers for fully saturated bio-WPCs. $\dagger$ The black line shows the calculated mean of the model from 100 Monte Carlo simulations (reproduced from Srubar et al. [12]). The dashed red line shows the ultimate strength of PHBV and the hashed region shows the projected reduced tensile strength due to degradation corresponding to $\sim 10$ $20 \%$ matrix weight loss [18-20]. (Color figure online)

this analysis does not account for loss of matrix and deterioration of the fiber-matrix interface due to enzymatic degradation. Imam et al. measured the degradation of tensile strength in PHBV and PHBV-starch composites during biodegradation in seawater and composting conditions [18-20]. With $\sim 10-20 \%$ weight loss in the material, they observed a reduction to $25-37 \%$ of original strength. With this reduction in tensile strength, the critical threshold for cracking could be expected to occur at a significantly lower fiber volume fraction, approximately $15-20 \%$, as shown by the hashed band in Fig. 2. Therefore, fragmentation due to moisture-induced damage during anaerobic degradation of the bio-WPCs used in this study may be expected to occur upon a bioplastic matrix weight loss around 10-20\%.

\section{Materials and Methods}

\section{Materials}

Avice ${ }^{\circledR}$ PH105 microcrystalline cellulose was used as a positive control for $\mathrm{AD} \mathrm{CH}_{4}$ production [39]. The average particle size was $20 \mu \mathrm{m}$, with particle diameters ranging from 5 to $30 \mu \mathrm{m}$ and a length-to-width aspect ratio of 2-3 [40]. PHBV pellets were from TiAnan, product code ENMAT Y1000P. The oak wood flour (OWF) used in these experiments was supplied by American Wood Fibers, Schofield, Wisconsin, USA under the trade name 2037-Oak. Fiber sieve analysis confirmed that the OWF was retained 
on a 20 mesh sieve, indicating a preprocessed OWF particle size of greater than $841 \mu \mathrm{m}$. Volumetric analysis showed an apparent (bulk) density of $0.44 \mathrm{~g} / \mathrm{cm}^{3}$. The average aspect ratio of the preprocessed OWF was 3.6, as measured using optical microscopy [14].

\section{Bio-WPC Fabrication and Treatments}

The composites studied in this work were: injection molded (1) neat PHBV, (2) PHBV-OWF, (3) PHBV-silanated OWF (sOWF), (4) maleated PHBV (mPHBV), and (5) $m$ PHBVOWF. The sample nomenclature and target and measured OWF fraction is given in Table 1. The full processing details for these composites are given in Srubar et al. [14], and further description of the fiber treatments is provided in Wright [41]. Prior to composite processing, a subset of the OWF had silane thermochemically vapor deposited onto the particles to render the particle surfaces hydrophobic. For the maleated samples, a subset of PHBV was set aside for reactive extrusion with maleic anhydride (MA) and dicumyl peroxide. These materials were dry blended and fed through a screw extruder under nitrogen $\left(\mathrm{N}_{2}\right)$. The grafted material was extracted to give $m \mathrm{PHBV}$ with a graft percentage of $0.8 \%$, creating hydrophilic linkages in the grafted portions of the polymer. These processed materials were used to make master batches, via extrusion, in various fiber percentages that were then injection molded into different sample geometries. Small rectangular prisms $(31.25 \mathrm{~mm} \times 6.2 \mathrm{~mm} \times 2.1 \mathrm{~mm})$ were used for degradation and biogas production measurements. Larger rectangular prisms $(150 \mathrm{~mm} \times 12.5 \mathrm{~mm} \times 6.5 \mathrm{~mm})$ were used for microscopy of the composites.

\section{Preparation of Anaerobic Media and Inoculum}

The anaerobic media used for these experiments was based primarily on standard solutions as described in ASTM D5210-92 [42], with modifications to concentrations based on other studies [43-45]. The following 4 concentrated stock solutions were used: (S1) resazurin, $0.5 \mathrm{~g} / \mathrm{L}$; (S2) $\mathrm{KH}_{2} \mathrm{PO}_{4}, 69 \mathrm{~g} / \mathrm{L}, \mathrm{K}_{2} \mathrm{HPO}_{4}, 88 \mathrm{~g} / \mathrm{L}, \mathrm{NH}_{4} \mathrm{Cl}, 100 \mathrm{~g} / \mathrm{L}$; (S3) $\mathrm{MgCl}_{2} \cdot 6 \mathrm{H}_{2} \mathrm{O}, 60 \mathrm{~g} / \mathrm{L}, \mathrm{CaCl}_{2} \cdot 2 \mathrm{H}_{2} \mathrm{O}, 45 \mathrm{~g} / \mathrm{L}, \mathrm{FeCl}_{2}, 12$ $\mathrm{g} / \mathrm{L}, \mathrm{MnCl}_{2} \cdot 4 \mathrm{H}_{2} \mathrm{O}, 400 \mathrm{mg} / \mathrm{L}, \mathrm{CoCl}_{2} \cdot 6 \mathrm{H}_{2} \mathrm{O}, 400 \mathrm{mg} / \mathrm{L}$,
$\mathrm{NiCl}_{2} \cdot 6 \mathrm{H}_{2} \mathrm{O}, 50 \mathrm{mg} / \mathrm{L}, \mathrm{CuCl}_{2}, 50 \mathrm{mg} / \mathrm{L}, \mathrm{ZnSO}_{4} \cdot 7 \mathrm{H}_{2}$ $\mathrm{O}, 105 \mathrm{mg} / \mathrm{L}, \mathrm{H}_{3} \mathrm{BO}_{3}, 50 \mathrm{mg} / \mathrm{L}, \mathrm{Na}_{2} \mathrm{MoO}_{4} \cdot 2 \mathrm{H}_{2} \mathrm{O}, 50$ $m g / L, \mathrm{Na}_{2} \mathrm{SeO}_{3}, 10 \mathrm{mg} / \mathrm{L}$; and (S4) $\mathrm{Na}_{2} \mathrm{~S} \cdot 9 \mathrm{H}_{2} \mathrm{O} 50 \mathrm{~g} / \mathrm{L}$. These 4 stock solutions were used in the same proportions as in ASTM D5210 to make the media, following the preparation instructions included in the standard. Bicarbonate $\left(\mathrm{NaHCO}_{3}\right)$ was added to give a final concentration of 50 $\mathrm{mM}$ in the media. The anaerobic media was continuously stirred and sparged with $\mathrm{N}_{2} / \mathrm{CO}_{2}$ 70:30 (Praxair certified standard, NI CD30C-K) during the addition of the inoculum to maintain anaerobic conditions. Anaerobic digester sludge was added as an inoculum to the anaerobic mineral media as 30 vol. $\%$ of the total volume.

Anaerobic inocula were collected from the anaerobic digesters at the San Jose Waste Water Treatment Plant in 4 $\mathrm{L}$ sample containers. These samples were stored in the dark at $37^{\circ} \mathrm{C}$ for 2 weeks prior to initiating experiments in order to reduce background activity from the sludge. Prior to testing, the sludge was screened through a $1 \mathrm{~mm}$ mesh sieve followed by a single layer of cheese cloth in order to reduce grit and large solids that may have interfered with the experiment. This step was performed immediately before adding the inoculum to the anaerobic media. Anearobic digester sludge and inoculated media were characterized in accordance with standard methods [46].

\section{Experimental Setup}

An Automatic Methane Test Setup (AMPTS I) from Bioprocess Control was used to measure $\mathrm{CH}_{4}$ production from the composites. Samples and positive ( $\alpha$-cellulose) and negative controls were prepared as described in Ryan et al. [37]; samples were measured in duplicate and the controls in triplicate. Each sample was placed in $500 \mathrm{~mL}$ media bottles ( $600 \mathrm{~mL}$ total volume), which were filled with 500 $\mathrm{mL}$ of inoculated anaerobic media, retaining a $100 \mathrm{~mL}$ gas headspace. The bottles were stoppered and the headspace was sparged with 70:30 $\mathrm{N}_{2} / \mathrm{CO}_{2}$ before and during filling to maintain anaerobic conditions in the sample container. The inoculated anaerobic media was continuously stirred during filling with a magnetic stirrer and gas agitation from being sparged with $\mathrm{N}_{2} / \mathrm{CO}_{2}$. Reactors were filled sequentially; media was pumped continuously with a bellows metering
Table 1 Bio-WPC sample nomenclature and targeted formulation [14]

\begin{tabular}{lllccccc}
\hline Sample & \multicolumn{2}{l}{ Target wt $\%$} & & & \multicolumn{2}{c}{ Measured OWF } \\
\cline { 2 - 3 } & PHBV & m PHBV & OWF & s OWF & & wt \% & vol \% \\
\hline P & 100.0 & 0 & 0 & 0 & 0 & 0 \\
P20 & 80.0 & 0 & 20 & 0 & 20.3 & 17.6 \\
P20S & 80.0 & 0 & 0 & 20 & 22.2 & 18.5 \\
2M & 98.0 & 2.0 & 0 & 0 & 0 & 0 \\
2M20 & 78.4 & 1.6 & 20 & 0 & 20.3 & 18.3 \\
\hline
\end{tabular}


pump (GRI 14251-003). Once filled, the bottles were connected with viton tubing to the AMPTS gas measuring setup. Bioreactors were maintained at $37^{\circ} \mathrm{C} \pm 2^{\circ} \mathrm{C}$ by keeping them in a temperature controlled room.

Gas sampling " $T$ 's" inline after the reactor headspace and before the carbon dioxide $\left(\mathrm{CO}_{2}\right)$ traps were used to sample the gas composition during degradation using gas chromatography. $\mathrm{CO}_{2}$ traps were added inline and filled with $3 \mathrm{M}$ sodium hydroxide with a thymolphthalein $\mathrm{pH}$ indicator. $\mathrm{CH}_{4}$ was measured volumetrically in calibrated reservoirs in increments of approximately $10 \mathrm{~mL}$. Data were logged using LabVIEW and calibrated, normalized, and corrected for negative control gas volume using the Matlab. The reactors were unmixed, based on prior work indicating that aggressive mixing may inhibit microbial adhesion on the composite substrates [47, 48].

\section{Solid Sampling}

Composite samples were removed from the bioreactors every 2 weeks for assessment of mass loss and 3D imaging using X-ray micro-computed tomography $(\mu \mathrm{CT})$. During the sampling process, gas collection lines were closed using a tubing crimp and bioreactors were removed from the $37^{\circ} \mathrm{C}$ room and loaded into a glove bag. The glove bag was alternatively evacuated under vacuum and filled with 70:30 $\mathrm{N}_{2} / \mathrm{CO}_{2}$ gas (3 times). All bioreactors were opened sequentially for sample removal. Samples were removed by screening through a $1 \mathrm{~mm}$ mesh sieve. Positive and negative control reactors were opened and agitated in a manner similar to what was experienced by the sample reactors during removal. Samples were surface dried using a Kimwipe, and removed from the glove bag through a sample port. Bioreactors sat in the glove bag (stoppered) at room temperature during imaging, approximately $4 \mathrm{~h}$. Prior to reintroducing the samples to the bioreactors, all samples were weighed so that sample mass loss could be compared to sample volume loss as measured in $\mu \mathrm{CT}$. Samples were then returned to the glove bag and loaded into the bioreactors. After all reactors were securely closed, the bag was opened and bioreactors were returned to the $37^{\circ} \mathrm{C}$ room, connected to the gas collection tubing, and crimps were opened so that gas measurement could recommence. Gas composition of the reactor headspace was measured using gas chromatography prior to composite removal.

\section{SEM}

In order to visualize how fiber-matrix interactions impact degradation, a scanning electron microscope (SEM) was used to image composites after being exposed to anaerobic microorganisms. Prior to imaging, liquid nitrogen $\left(\mathrm{LN}_{2}\right)$ fractured samples were suspended in covered anaerobic digester sludge for 10 days. The samples were then rinsed with deionized (DI) water, dried in a vacuum desiccator for 1 week, and prepared for imaging. Both as-fractured crosssections and degraded cross-sections were affixed to standard specimen mounts using DAG0T-502 carbon paint and coated with Au60Pd40 alloy using a Gressington sputter coater operated at $20 \mathrm{~mA}$ for $45 \mathrm{~s}$. Samples were imaged using a FEI XL30 Sirion SEM at 5kV. Samples were coated and imaged at the Stanford Nano Shared Facilities (SNSF).

\section{Micro-CT}

$\mathrm{X}$-ray micro-computed tomography $(\mu \mathrm{CT})$ was used to assess the physical extent of composite degradation, by providing 3D images of the surface and internal structure of the composites. An Inveon ${ }^{\mathrm{TM}}$ preclinical multimodal CT scanner (Siemens Model No. 10119223) was used for these measurements. The voxel size of these scans was 50 $\mu \mathrm{m}$. Scans were calibrated to Houndsfield units (HU) using a calibration standard with air, water, bone, and polyethylene (water is $0 \mathrm{HU}$ at STP, air is $-1000 \mathrm{HU}$ ). Surface dried samples were loaded onto the imaging bed along with an un-degraded neat PHBV control sample that was used to calibrate intensity, corresponding to X-ray density, between scans.

Inveon Research Workplace (IRW) was used for initial image analysis. These functions included: cropping, establishing density-related intensity cutoffs, creating region of interest (ROI) volumes containing the composite specimens, and masking out interference from the bed and other samples. IRW was then used to co-register progressively degraded composite samples and export ROI volumes. Subsequent volume and surface area analysis was performed using Amira. Composite surface area and volume measurements were compared to weight loss and biogas production trends. These measurements and analyses were performed at the Stanford Small Animal Imaging Facility.

\section{Model Evaluation}

$\mathrm{CH}_{4}$ production data were collected using Labview and calibrated, normalized to initial mass, corrected for negative control $\mathrm{CH}_{4}$ volume, and converted into percent of theoretical $\mathrm{CH}_{4}$ production for PHBV using Matlab. Mass loss data were converted to percent of initial mass lost. For both $\mathrm{CH}_{4}$ and mass loss, the Gompertz model (Eq. 1) was fit to the pooled data for each sample type using the Levenberg-Marquardt algorithm for non-linear least-squares in the CurveFitting application in Igor Pro 6.37. Upper and lower 95 $\%$ confidence and prediction intervals and goodness of fit were calculated for all fit parameters. This confidence interval is shown as an estimate of error in the plots of the rate parameters for the samples. 


\section{Results and Discussion}

\section{Fiber-Matrix Interface Effects}

The interaction of the fiber with the polymer matrix can impact both moisture absorption and anaerobic degradation in the bio-WPCs. Prior work indicates that the two compatibilization treatments: (1) silane treatment to create a hydrophilic coating on the WF and (2) adding hydrophilic linkages with the MA-grafted PHBV, do impact the fiber-matrix interface [14]. Figure 3 shows SEM images of the fiber-matrix interface for the PHBV-20\% OWF (P20), PHBV-20\% sOWF (P20S), and $m$ PHBV-20\% OWF (2M20) composites as-fractured and after being exposed to anaerobic degradation for 10 days. The width of the gap between the WF and the PHBV in the as-fractured samples is one measure of interfacial compatibility. The measured gap between the fiber and polymer matrix yielded widths of: $1.36 \pm 1.3 \mu \mathrm{m}$ for $\mathrm{P} 20,0.26 \pm 0.13 \mu \mathrm{m}$ for P20S, and 1.59 $\pm 1.38 \mu \mathrm{m}$ for $2 \mathrm{M} 20$. Interfacial incompatibility, as evidenced by a relatively large gap between the fiber and the PHBV matrix, can be seen in Fig. 3a for the P20 composite. The silane-treated fiber in Fig. $3 \mathrm{~b}$ shows increased wettability with polymer, with a markedly lower gap width than observed for P20 and 2M20 composites. This reduction in interfacial gap is attributed to the nature of the silane treatment on the WF, which provides a uniform coating on the fiber surface and increases the hydrophobicity of the fiber surface [41, 49]. Even though the measured gaps of the 2M20 composites and the P20 composites were similar, the maleated samples had evidence of polymer matrix tethers to the WF, not observed in the other composites (Fig. 3c). This observation aligns with the expectation that there would be independent maleated domains oriented toward the WF from the bulk PHBV matrix, and that the $m$ PHBV can also covalently bond to the WF [41, 50]. Increased fiber-matrix bond was also supported by the mechanical response data for both of these composites [14].

The gap widths also give an indication of how microbial degradation could be expected to proceed in the bioWPCs, based on scale. The mean gap width for P20S, the narrowest measured gap, is approximately 26-78 times larger than the expected diameter of PHBV depolymerase, with several of the cited poly(hydroxyalkanoate) (PHA) depolymerases in the range of $28-58 \mathrm{kDa}$ [51-53]. This weight corresponds to an approximate enzyme diameter of 4-5 nm [54]. By contrast, a typical microorganism in this system would be expected to be between 0.1 and $10 \mu$ $\mathrm{m}[55,56]$. In most cases this typical size would be larger than the 1.3-1.5 $\mu \mathrm{m}$ gap observed for the P20 and 2M20

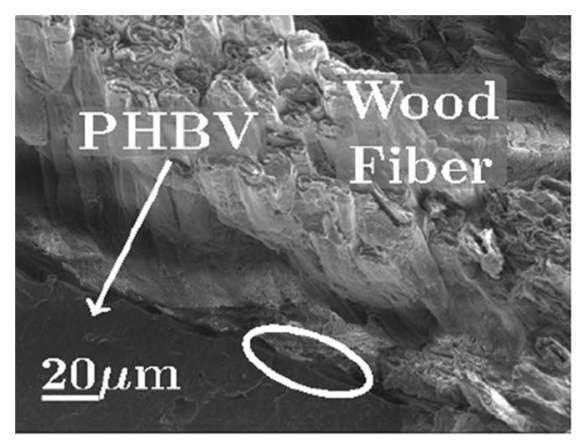

(a) P20 (as-fractured)

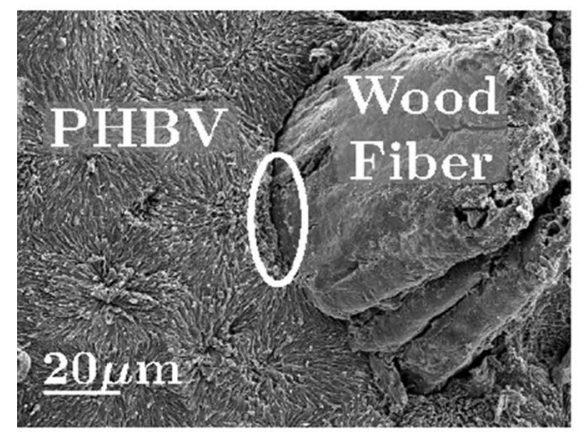

(d) P20 (degraded)

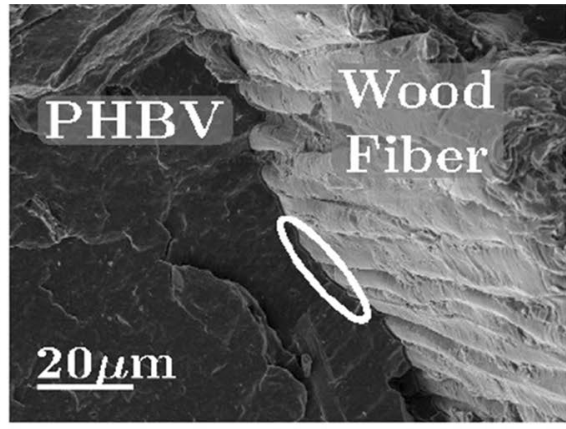

(b) P20S (as-fractured)

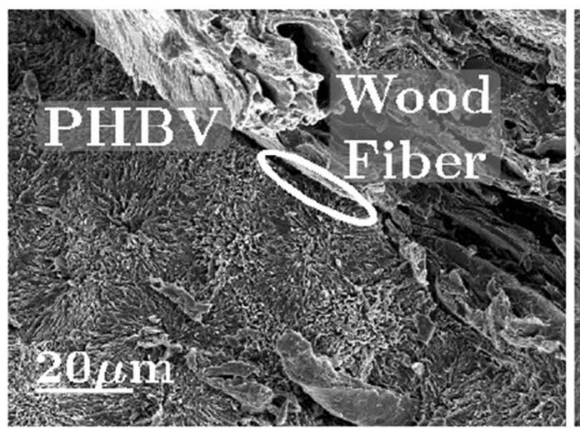

(e) P20S (degraded)

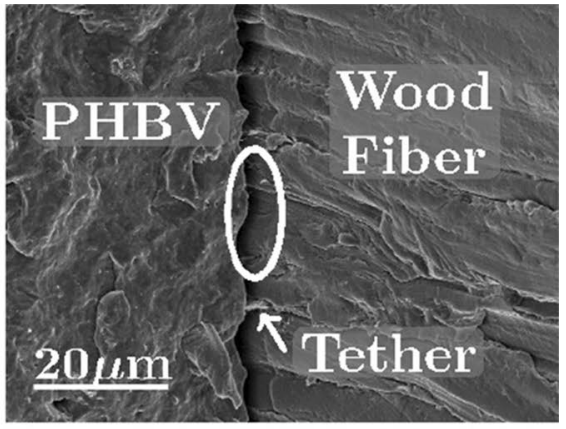

(c) 2M20 (as-fractured)

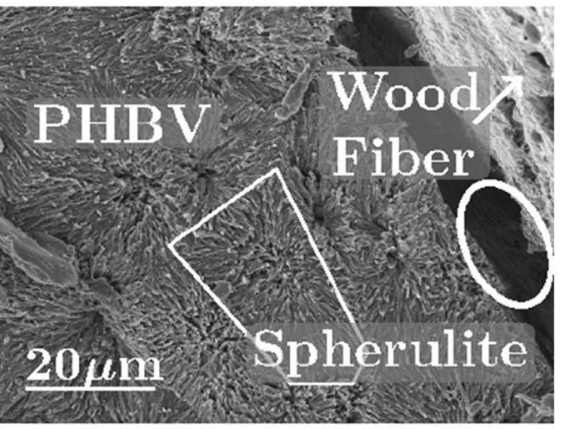

(f) $2 \mathrm{M} 20$ (degraded)
Fig. 3 SEM micrographs of composite samples as-fractured (top) and after 10 days of anaerobic degradation (bottom) with the fracture surface exposed. The fiber-matrix interface (gap) is circled in each image. Gap widths: $1.36 \pm 1.3 \mu \mathrm{m}$ for P20, $0.26 \pm 0.13 \mu \mathrm{m}$ for P20S, and $1.59 \pm 1.38 \mu \mathrm{m}$ for $2 \mathrm{M} 20$ 
composites, although microorganisms in the 0.1-2 $\mu \mathrm{m}$ range might have increased accessibility to the interfacial space in these composites as compared to the P20S composites. For all of the bio-WPCs, the interfacial regions would primarily only initially be accessible to water and enzymes, with microbial colonization occurring as larger voids are opened up via surface erosion or fragmentation. As can be seen in Fig. 3d-f, and as others have observed, preferential enzymatic degradation of amorphous regions of the PHBV reveals the underlying spherulitic microstructure $[34,57]$. Maleation was not observed to impact the formation of the spherulite structure of the PHBV.

\section{Mass Loss and $\mathrm{CH}_{4}$ Production}

Figure 4 shows mass loss and $\mathrm{CH}_{4}$ production during anaerobic degradation of neat PHBV, PHBV-20\% OWF, PHBV-20\% SOWF, $m$ PHBV, and $m$ PHBV-20\% OWF. The Gompertz model is shown with data from duplicate samples, and is an average fit function for both sets of data. Because the particle fraction of the OWF was smaller than the $1 \mathrm{~mm}$ mesh size used to collect the samples at each measurement interval, mass loss in both the bioplastic and bio-WPCs is expected to reach $100 \%$ with complete anaerobic biodegradation. Full biodegradation based on the mass lost occurred in bioplastics and bio-WPCs between 4 and 6 weeks.

The $\mathrm{CH}_{4}$ production is not expected to reach $100 \%$ of the theoretical value in the neat and maleated PHBV because some of the carbon and energy are used for cell synthesis. Neat PHBV and $m$ PHBV produced 94 and $95 \%$ of their respective theoretical $\mathrm{CH}_{4}$ yields. In the composites, incomplete mineralization of the lignocellulosic biomass to $\mathrm{CH}_{4}$ additionally reduced $\mathrm{CH}_{4}$ yield. The $\mathrm{P} 20,2 \mathrm{M} 20$, and P20S bio-WPCs produced 84,88 , and $83 \%$ of their respective theoretical yields. In order to easily compare the percent $\mathrm{CH}_{4}$ produced with mass loss in Fig. $4, \mathrm{CH}_{4}$ production is scaled to $P_{m}$, the theoretical total production yield. As discussed in section "Model for Mass Loss and Methane Production", a mass loss of approximately 10-20\% in the composites is expected to lead to accelerated fiber swelling-induced matrix damage, which occurs between $7-14$ days in the samples.

The maximum rate parameter values from the Gompertz model for weight loss and $\mathrm{CH}_{4}$ production are shown in Fig. $5 \mathrm{a}$ in percent per day. There are statistically significant differences between the rate of $\mathrm{CH}_{4}$ production and weight loss for all of the composite sample types. The incomplete mineralization of lignocellulosic material in the WF is part of this difference. However, there is also an increasing rate observed from P20 to 2M20 to P20S composites, indicating that the different compatibilization treatments affect the rate of mass loss. Relative comparisons between the composites are facilitated by normalizing to neat PHBV for weight loss and $\mathrm{CH}_{4}$ production, as is shown in Fig. 5b. In particular, it appears that the P20S samples experience a rapid physical disintegration as compared to the other samples. The P20S composites' maximum rate of degradation, determined from weight loss, is approximately $92 \%$ greater than that of the untreated composites, and the $2 \mathrm{M} 20 \mathrm{com}-$ posites' maximum rate is approximately $30 \%$ greater. All composites had a higher maximum rate than the PHBV by a factor of 1.2-2.3. If the surface erosion mechanism were solely contributing to degradation in the composites, water transport bringing enzymes progressively from the outside of the sample inwards would control the degradation rate. The compatibilization treatments could then be expected to slow moisture uptake in the treated composites with respect to the untreated composites [15]. That there is rapid weight loss in the composites, and the compatibilized composites in particular, indicates that there is damage caused by fiberswelling which results in fragmentation of the composites, as discussed in section "Fiber-Saturation Modeling Applied to Degradation“. The treatments therefore act to not only slow moisture uptake while in-service, but to enhance degradation rate as well.

\section{D Visualization of Degradation}

The progressive degradation of PHBV (P), and PHBV-20\% OWF (P20) at 0,2 , and 4 weeks is shown as three cross sections in Fig. 6. Increased roughness and progression of the degradation front is observed in the $20 \%$ composite as compared to neat PHBV. The presence of OWF appears to create channels into the composite during degradation leading to more rapid sample degradation for the composite. In both samples, degradation does not progress evenly inwards from all composite fronts. This unevenness is likely due to skin effects (due to more rapid cooling of the polymer melt at the mold surface) and other local material differences due to the injection-molding process [58, 59], with additional inhomogeneity introduced by the OWF in the composite samples. Localization of initial colonization and degradation may also contribute to the roughness of the front.

Figure 7 shows cross sections of P20, P20S, and 2M20 bio-WPC samples after 2 weeks of degradation, approximately the period of time when cracking is expected to initiate in the samples. Large cracks can be seen initiating from the lower left of the P20S composite in Fig. 7b. As discussed in sections "Fiber-Saturation Modeling Applied to Degradation" and "Mass Loss and $\mathrm{CH}_{4}$ Production", an increased susceptibility to moisture damage in the treated composites was observed [12], including greater swelling in the P20S and 2M20 composites than in the P20 samples, and the observation of visual 


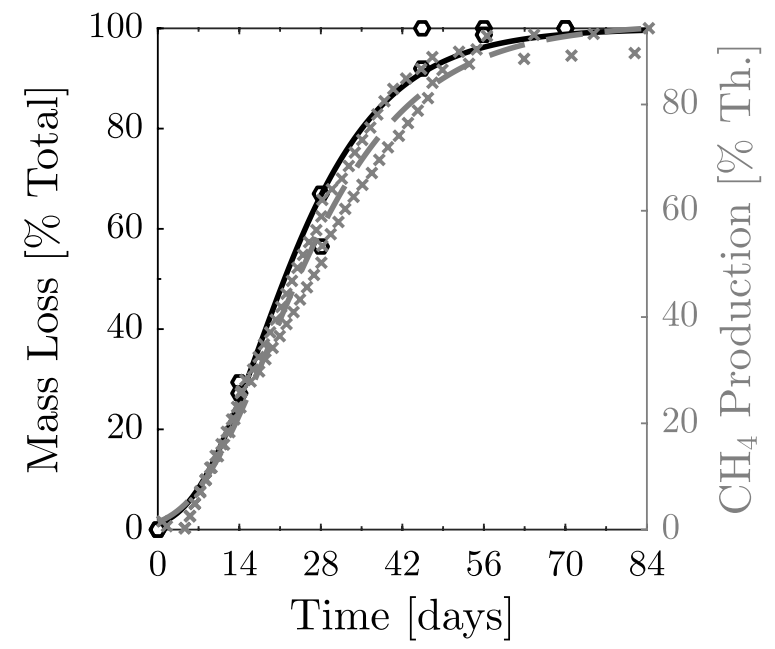

(a) $\mathrm{P}$

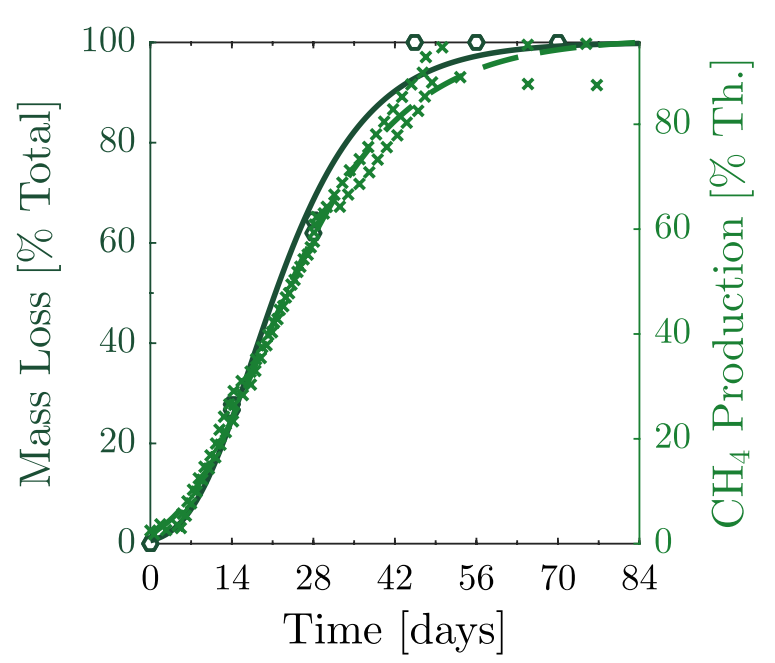

(c) $2 \mathrm{M}$

Legend

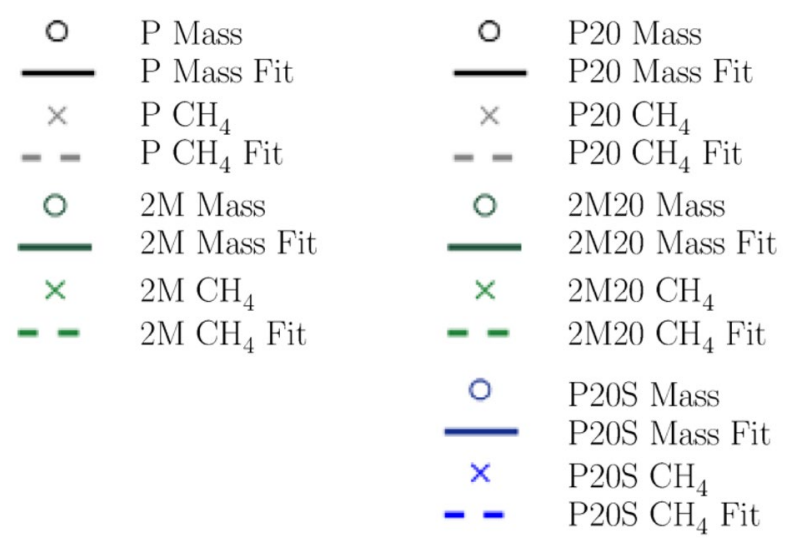

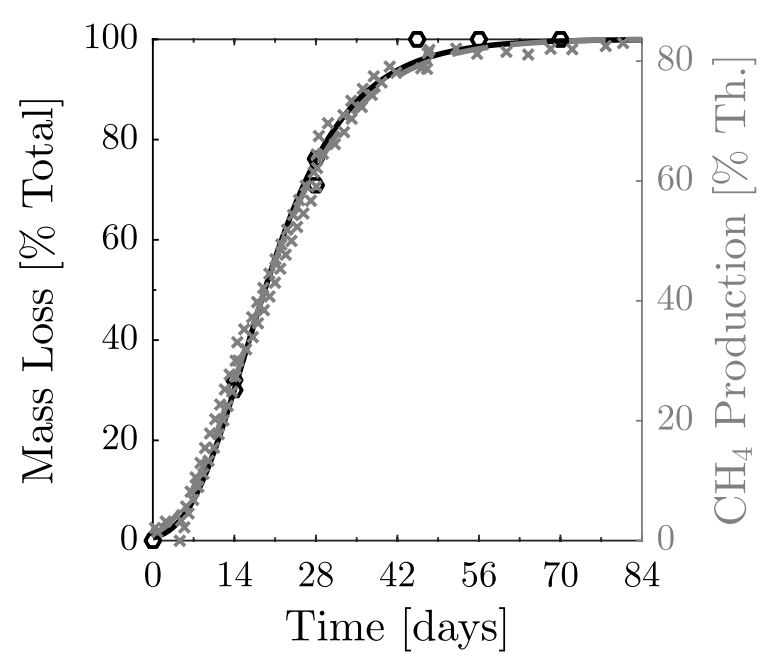

(b) P20

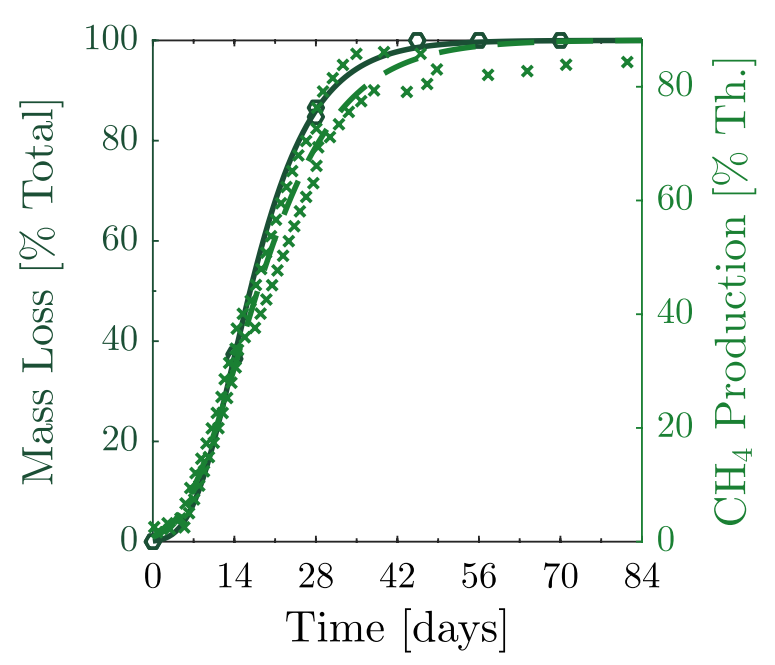

(d) $2 \mathrm{M} 20$

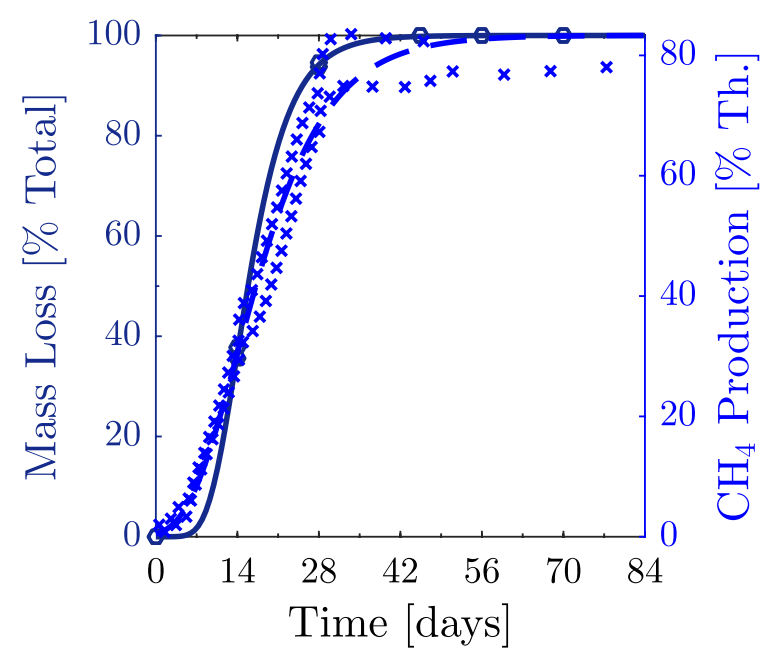

(e) P20S

Fig. 4 Percent mass loss and $\mathrm{CH}_{4}$ production over time for neat PHBV (P), PHBV-20\% OWF (P20), $m$ PHBV (2M), $m$ PHBV-20\% OWF (2M20), and PHBV-20\% sOWF. Mass loss and $\mathrm{CH}_{4}$ were measured in duplicate, model fits are of the pooled data sets 

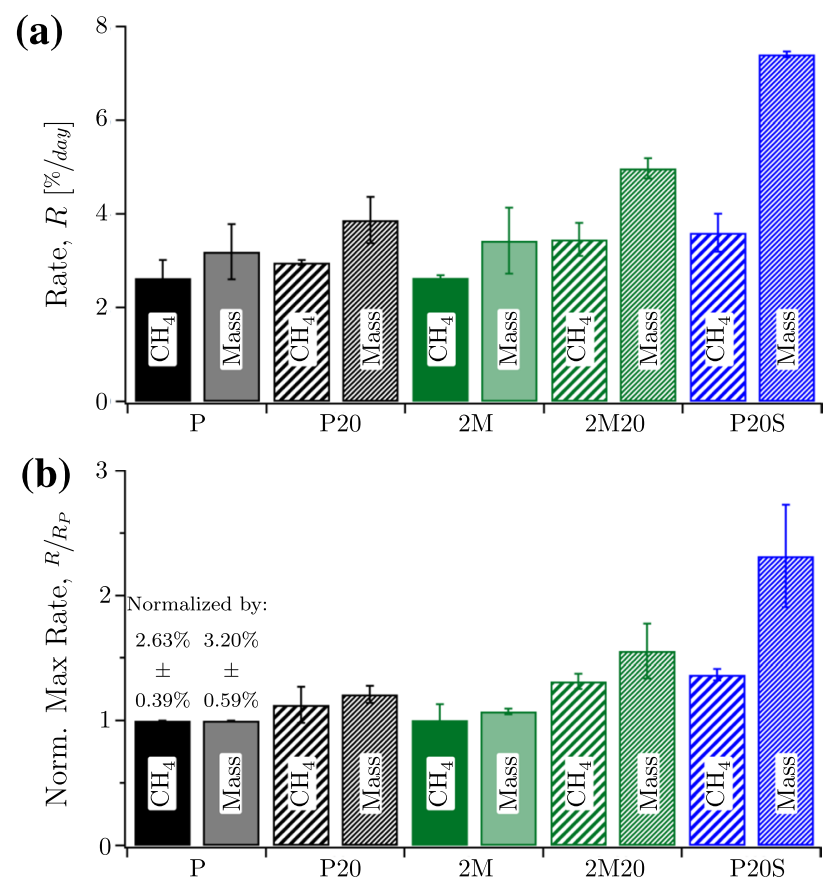

Fig. 5 a The maxiumum rate of $\mathrm{CH}_{4}$ production $\left(\mathrm{CH}_{4}\right)$ and mass loss (Mass) in percent per day. $\mathbf{b}$ The normalized maximum rate of $\mathrm{CH}_{4}$ production $\left(\mathrm{CH}_{4}\right)$ and mass loss (Mass). Rates are normalized to that of PHBV $\left(R / R_{P\left(\mathrm{CH}_{4}, \text { Mass }\right)}\right), R_{P\left(\mathrm{CH}_{4}\right)}=2.63 \pm 0.39$ and $R_{P(\text { Mass })}=$ $3.20 \pm 0.59 \%$. Error bars show a the $95 \%$ confidence interval for the parameter fit and $\mathbf{b}$ the propagated error for the normalized values (2 pooled data sets for each sample type)
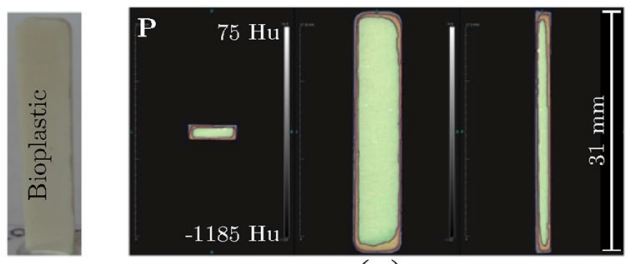

(a)
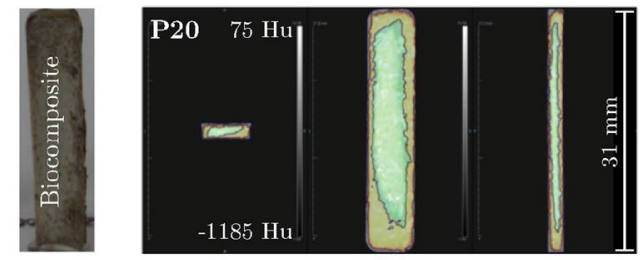

(b)

Fig. $6 \mu \mathrm{CT}$ images showing sample loss over time (0, 2, and 4 weeks of degradation). a PHBV (P) sample and b PHBV/20\% OWF (P20). ROI outlines show the degradation front as samples are progressively degraded

surface cracks with the order of least to greatest cracking as $\mathrm{P} 20<2 \mathrm{M} 20<\mathrm{P} 20 \mathrm{~S}$. Likewise, mass loss rates $(R)$ during anaerobic degradation were also observed in the order of $R_{\mathrm{P}}=R_{2 \mathrm{M}}<R_{\mathrm{P} 20}<R_{2 \mathrm{M} 20}<R_{\mathrm{P} 20 \mathrm{~S}}$. The reduced fiber-matrix gap in the P20S samples may be one reason this composite is particularly susceptible to damage related to fiber swelling, leaving less room to accommodate expansion without stressing the matrix. However, the other composites do not show conclusive evidence of moisture-induced cracking at approximately 10-20\% matrix loss (occurs between 7-14 days, Fig. 4, left axis), as predicted in section "Theory". This result indicates that a more complex analysis of the interaction between moisture absorption rate, time to fiber saturation, and degradation rate is required to more accurately predict time to onset of cracking.

Figure 8 shows the surface area to volume ratio, calculated from the $\mu \mathrm{CT}$ images, of the composites versus the neat PHBV and $m$ PHBV samples. The composite samples show a more rapid increase than the neat samples. As observed in the volume cross-sections (Fig. 6), degradation exposes a progressively roughened surface over time. Rapid physical sample loss occurs between 2-4 weeks in the P20S samples and between 4-6 weeks for the other sample types, following the observed mass loss rate $\left(R_{\mathrm{P}}=R_{2 \mathrm{M}}<R_{\mathrm{P} 20}<R_{2 \mathrm{M} 20}<R_{\mathrm{P} 20 \mathrm{~S}}\right)$.

We attribute much of the composites' susceptibility to physical degradation to increased deterioration from moisture-induced cracking, accelerated by microbial degradation of the bioplastic. This cracking opens up additional pathways in the composite for accelerated moisture-uptake, microbial ingress, along with potential internal voids where $\mathrm{CH}_{4}$ may build up. Subsequent cracking and degradation of the polymer matrix occurs, leading to the large mass loss rates and modestly increased $\mathrm{CH}_{4}$ production rates are observed in the bio-WPCs. These effects are most notable in the silane-treated, P20S, samples.

\section{Conclusions}

This work describes our investigation of moisture-induced fragmentation in the anaerobic degradation of biodegradable WPCs (bio-WPC). We found that both the silane and maleation treatments acted to not only slow moisture uptake, as previously shown [14], but enhance the rate of biodegradation as well. In all cases, the maximum rate of degradation in composite samples was greater than that of neat PHBV. We attribute this enhancement to fibers in the bioplastic matrix of the composites creating additional pathways for moisture, enzymatic, and microbial ingress which leads to fiber swelling, increased damage at the fiber-matrix interface, and cracking, further accelerating degradation. Degradation was measured with mass loss and $\mathrm{CH}_{4}$ production, and fit using the Gompertz model, previously found to provide a good fit for $\mathrm{CH}_{4}$ production data from AD of PHBV [27]. The accelerated degradation of 
Fig. $7 \mu \mathrm{CT}$ cross sections of a P20, b P20S, and c $2 \mathrm{M} 20$ at 2 weeks. Note the large cracks forming from the surface of the P20S sample inward
Mass Loss: $31 \%$

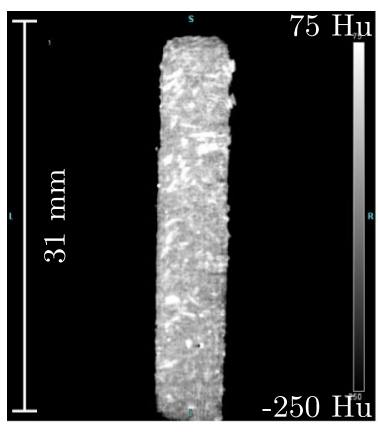

(a) P20

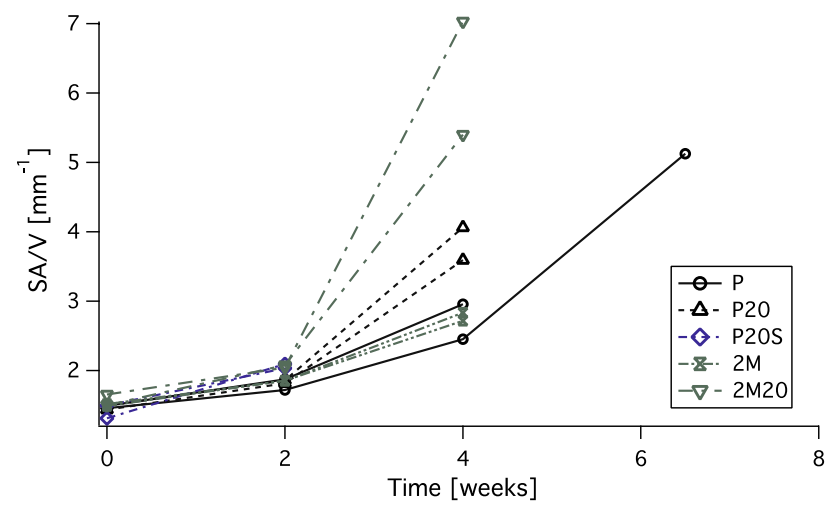

Fig. 8 Surface area to volume ratio as computed from $\mu \mathrm{CT}$ imaging of composite samples during degradation. Like mass loss rate, surface area to volume ratios also increased as $\mathrm{P}=2 \mathrm{M}<\mathrm{P} 20<2 \mathrm{M} 20$ $<\mathrm{P} 20 \mathrm{~S}$

the composites manifests in the following ways. First, we observed higher rates of mass loss and $\mathrm{CH}_{4}$ production for bio-WPCs as compared to neat PHBV, by a factor of 1.2-2.3. Second, the rates of mass loss and $\mathrm{CH}_{4}$ production track previously described moisture-induced damage [12], showing a statistically significant increase in mass loss rates $(R)$ for $R_{\mathrm{P}}=R_{2 \mathrm{M}}<R_{\mathrm{P} 20}<R_{2 \mathrm{M} 20}<R_{\mathrm{P} 20 \mathrm{~S}}$. The maximum rate of anaerobic biodegradation was enhanced by $30 \%$ for the maleic anhydride treatment and $92 \%$ for the silane treatment over untreated samples. Third, there was a statistically significant deviation in maximum $\mathrm{CH}_{4}$ production rate and mass loss rate in the composite samples, indicating that fragmentation was occurring. And last, onset of cracking in the silane-treated composites was observed at 14 days, which corresponds to the maximum rate of change in mass loss and the expected onset of a degraded PHBV matrix exposed to moisture-induced fiber swelling. This link between moisture-induced fiber swelling and degradation suggests that cracking plays a significant role in the degradation process and that fiber content and moisture availability during degradation can be used
Mass Loss: $37 \%$

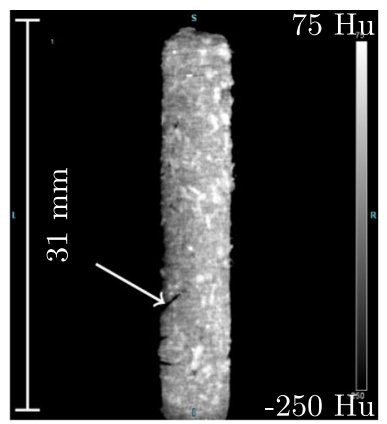

(b) P20S

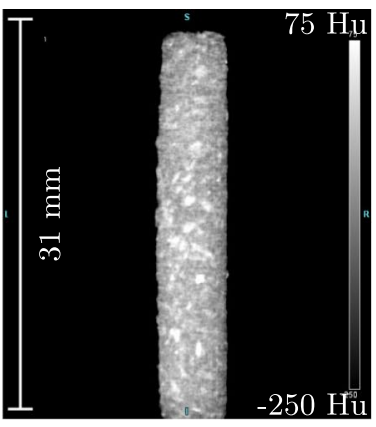

(c) $2 \mathrm{M} 20$
Mass Loss: $36 \%$

to target optimal mass loss conditions and $\mathrm{CH}_{4}$ production from an $\mathrm{AD}$ system. This relationship is also important for in-service applications where degradation of the outer bioplastic matrix may occur over time, either due to microbial or other degradation mechanisms.

Acknowledgements The authors thank BioProcess Control, SeaHold LLC, and Team Biogas for their generous support and collaboration with the AMPTS unit. We also thank the City of San Jose and the employees of the San Jose Waste Water Treatment Plant for their assistance in obtaining inoculum for these experiments. Part of this work was performed at the Stanford Nano Shared Facilities (SNSF) and Soft and Hybrid Materials Facility (SMF) at Stanford University. Micro-CT imaging and analysis were performed at the Stanford Small Animal Imaging Facility, and in particular we thank Dr. Timothy Doyle for his expertise in establishing scan conditions and analysis and Dr. Frezghi Habte for his assistance in data analysis. This work was funded by NSF CMMI [Grant 0900325], California EPA Department of Toxic Substances Control [Project Ref. No. 07T3451], CalRecycle [Contract No. DRRR10020], and individual graduate funding from the EPA Star Graduate Fellowship and the Stanford Civil Engineering Charles H. Leavell Graduate Fellowship.

\section{References}

1. Flores-Hernández M, Reyes González I, Lomelí-Ramírez M, Fuentes-Talavera F, Silva-Guzmán J, Cerpa-Gallegos M, GarcíaEnríquez S (2014) J Compos Mater 48:209

2. F. Associates (1998) Characterization of building-related construction and demolition Debris in the United States, Tech Rep EPA530-R-98-010, U.S. Environmental Protection Agency

3. AIA Sustainability Discussion Group (2008) Construction waste management strategies. Tech Rep BP 10.05.36, American Institute of Architects

4. Office of Resource Conservation and Recovery (5306P) (2015) Adv Sustain Mater Manag Facts and Figures Report, Tech Rep EPA530-R-15-002, U.S. Environmental Protection Agency

5. Miller SA, Srubar WV III, Billington SL, Lepech MD (2015) Resour Conserv Recycl 99:72

6. Netravali AN, Chabba S (2003) Mater Today 6:22

7. Rostkowski KH, Criddle CS, Lepech MD (2012) Environ Sci Technol 46:9822

8. Avella M, Rota G, Martuscelli E, Raimo M, Sadocco P, Elegir G, Riva R (2000) J Mater Sci 35:829 
9. Teramoto N, Urata K, Ozawa K, Shibata M (2004) Polym Degrad Stab 86:401

10. Felton CC, De Groot C (1996) Rodney. For Prod J 46:37

11. Bismarck A, Mohanty AK, Aranberri-Askargorta I, Czapla S, Misra M, Hinrichsen G, Springer J (2001) Green Chem 3:100

12. Srubar W, Billington S (2013) Compos Part A 50:81

13. Srubar WV III, Miller SA, Lepech MD, Billington SL (2014) Constr Build Mater 71:589

14. Srubar WV III, Pilla S, Wright ZC, Ryan CA, Greene JP, Frank CW, Billington SL (2012) Compos Sci Technol 72:708

15. Srubar WV, Frank CW, Billington SL (2012) Polymer 53:2152

16. Molitoris HP, Moss ST, De Koning G, Jendrossek D (1996) Appl Microbiol Biotechnol 46:570

17. Kyrikou I, Briassoulis D (2007) J Polym Environ 15:125

18. Imam S, Gordon S, Shogren R, Greene R (1995) J Environ Polym Degr 3:205

19. Imam S, Chen L, Gordon S, Shogren R, Weisleder D, Greene R (1998) J Environ Polym Degr 6:91

20. Imam S, Gordon S, Shogren R, Tosteson T, Govind N, Greene R (1999) Appl Environ Microbiol 65:431

21. Calderón K, González-Martínez A, Gómez-Silván C, Osorio F, Rodelas B, González-López J (2013) Int J Mol Sci 14:18572

22. Zwietering M, Jongenburger I, Rombouts F, Van't Riet K (1990) Appl Environ Microbiol 56:1875

23. López S, Prieto M, Dijkstra J, Dhanoa M, France J (2004) Int J Food Microbiol 96:289

24. Ghatak MD, Mahanta P (2014) Carbon 63:35

25. Lay J-J, Li Y-Y, Noike T (1996) Doboku Gakkai Ronbunshu 1996:101

26. Lay J-J, Li Y-Y, Noike T (1998) J Environ Eng 124:730

27. Ryan CA, Billington SL, Criddle CS (2017) Bioresour Technol 227:205

28. Gordon S, Imam S, Shogren R, Govind N, Greene R (2000) J Appl Polym Sci 76:1767

29. Tong X, Smith LH, McCarty PL (1990) Biomass 21:239

30. Barlaz M (2006) Waste Manag 26:321

31. Budwill K, Fedorak PM, Page WJ (1992) Appl Environ Microbiol 58:1398

32. Reischwitz A, Stoppok E, Buchholz K (1998) Biodegradation 8:313

33. Shin P, Kim M, Kim J (1997) J Polym Environ 5:33

34. Gutierrez-Wing MT, Stevens BE, Theegala CS, Negulescu II, Rusch KA (2010) J Environ Eng 136:709

35. Nishida H, Tokiwa Y (1993) J Polym Environ 1:65

36. Tokiwa Y, Calabia B (2007) J Polym Environ 15:259

37. Ryan CA, Billington SL, Criddle CS (2017) Compos Part A 95:388
38. Stark N (2001) J Thermoplast Compos Mater 14:421

39. ASTM, D5526-94 (2002) Standard test method for determining anaerobic biodegradation of plastic materials under accelerated landfill conditions. ASTM International, West Conshohocken

40. Katdare A, Chaubal M (2006) Excipient development for pharmaceutical, biotechnology, and drug delivery systems. CRC Press, Boca raton

41. Wright ZC (2013) Poly(hydroxybutyrate-co-valerate) biodegradable foams the effects of processing, nanoscale additives, and aging. Ph.D. thesis, Stanford University, Stanford

42. ASTM, D5210-92(2007): Standard test method for determining the anaerobic biodegradation of plastic materials in the presence of municipal sewage sludge, ASTM International (2007)

43. Shelton DR, Tiedje JM (1984) Appl Environ Microbiol 47:850

44. Wu WM, Hickey RF, Zeikus JG (1991) Appl Environ Microbiol $57: 3438$

45. Kenealy W, Zeikus JG (1981) J Bacteriol 146:133

46. Association American Public Health (1998) American Water Works Association and Water Environment Federation. American Public Health Association, Standard Methods for the Examination of Water and Wastewater

47. Gartiser S, Wallrabenstein M, Stiene G (1998) J Environ Polym Degr 6:159

48. Morse MC (2010) Anaerobic biodegradation of biocomposites for the building industry. Ph.D. thesis, Stanford University, Stanford

49. George J, Sreekala MS, Thomas S (2001) Polym Engi Sci 41:1471

50. Anderson SP (2007) Wood fiber reinforced bacterial biocomposites: effects of interfacial modifiers and processing on mechanical and physical properties. Ph.D. thesis, Washington State University, Pullman

51. Behrends A, Klingbeil B, Jendrossek D (1996) FEMS Microbiol Lett 143:191

52. Calabia BP, Tokiwa Y (2006) Biotechnol Lett $28: 383$

53. Gangoiti J, Santos M, Prieto MA, de la Mata I, Serra JL, Llama MJ (2012) Appl Environ Microbiol 78:7229

54. Erickson HP (2009) Biol Proced Online 11:32

55. Narihiro T, Sekiguchi Y (2007) Curr Opin Biotech 18:273

56. Bergey DH, Whitman WB, Goodfellow M, Kämpfer P, Busse H-J (eds) (2012) Bergey's manual of systematic bacteriology. Springer, New York

57. Morse MC, Liao Q, Criddle CS, Frank CW (2011) Polymer 52:547

58. Joseph EG, Wilkes GL, Baird DG (1985) Polym Eng Sci 25:377

59. Corrêa M, Rezende M, Rosa D, Agnelli J, Nascente P (2008) Polym Test 27:447 